\title{
What is the optimal caesarean section rate? An outcome based study of existing variation
}

\author{
Michael Joffe, Jean Chapple, Catherine Paterson, R W Beard
}

\begin{abstract}
Study objective - To investigate the consequences of different levels of caesarean section (CS) rate in terms of fetal and maternal outcomes.

Design - Comparison of outcome variables between four categories of maternity units stratified according to CS rates. Data were collected concurrently.

Settings - All 17 maternity units in one health region.

Subjects - Data for the perinatal mortality analysis: all 221867 deliveries in 1983-87 (excluding severe malformations) (1462 deaths); maternity information analysis system: all 36727 women with singleton pregnancies who delivered in 1988.
\end{abstract}

Outcome measures - Perinatal mortality, Apgar scores at one and five minutes, onset of respiration after one minute, postnatal transfusion, postnatal infection, thromboembolism, low haemoglobin concentration at discharge, and puerperal psychosis were determined.

Results - Teaching hospitals with an increased proportion of high risk cases had the highest CS rate, but the other three categories were found to serve comparable populations. Perinatal mortality showed a birthweight specific pattern for very low birthweight infants, but not for other deliveries, mortality rates were lower in units with higher CS rates. Apgar scores showed no trend, but the onset of respiration after one minute was significantly more frequent in units with a CS rate of less than $10 \%$. Increased maternal postnatal blood transfusion was associated with higher CS rates but no trend was observed for the other maternal variables.

Conclusions - CS rates in general maternity units should be 10 to $12 \%$ or lower in the singleton population as a whole, but a more interventionist approach is indicated for very low birthweight infants. If confirmed, these recommendations could easily be incorporated into clinical audit.

( $\mathcal{F}$ Epidemiol Community Health 1994;48:406-411)

There is considerable variation in the rate of caesarean section (CS), both internationally and, to a lesser extent, within countries. A recent study from Detroit reported that the rate ranged from $19 \cdot 1-42 \cdot 3 \%$, the variation being attributed largely to the mode of practice of the attending physician. ${ }^{1}$ In $1982,18.5 \%$ of deliv- eries in the USA were by CS, compared with $10.1 \%$ in England and Wales and $5.3 \%$ in The Netherlands. ${ }^{2}$ In each of these places, there has been a steady increase in the rate since the late 1960 s or before, with a more than 2.5 fold rise since 1968. In 1968 the rates for the USA, England and Wales, and The Netherlands were $5.3 \%, 4.0 \%$ and $1.8 \%$, respectively. ${ }^{3}$ In England and Wales, regional rates varied from $8.7 \%$ (Trent Health Region) to $12.0 \%$ (South West Thames Health Region) in $1985 .{ }^{4}$ The variation between individual maternity units within each region is almost certainly greater, but is not documented in national figures.

There have been numerous studies of the determinants of variation in rates. ${ }^{15-9}$ In North West Thames Regional Health Authority, we have found that the CS rate increases with increasing age and body mass index, and with decreasing height and birthweight, and is lower in white women than in other ethnic groups. ${ }^{10}$ There has also been considerable discussion of the variation in rates, both among interested and concerned non-obstetricians ${ }^{11}$ and within the obstetric profession itself. In North America, concerted efforts have been made to reduce the CS rate, which is widely perceived as excessively high. ${ }^{12}$

There is, however, little information on the consequences of differing CS rates in terms of their effects on appropriate outcome variables. It is important to avoid unnecessary operative intervention, as CS produces an increase in maternal morbidity, as well as consuming extra resources. ${ }^{13}$ Although in many countries the rates have risen during the same period as perinatal mortality has fallen, an improvement in mortality was achieved in Dublin with little change in the CS rate. ${ }^{14}$ Thus, the existence of a causal connection is an open question. A study of the 1977 California birth cohort found that the CS rate was inversely related to perinatal mortality, adjusted for birthweight and other factors, ${ }^{15}$ but the results were dominated by heterogeneity among the types of hospital, and the findings probably represent the unadjusted confounding effects of socioeconomic status.

Thus, it remains unclear what the optimal CS rate should be. An observational research method is appropriate to answer this question, as it allows the study of effectiveness during the course of actual, routine practice. It has the limitation that confounding factors and selection effects may interfere with the study, and the analysis therefore needs to take account of these possibilities. However, these drawbacks are intractable only in studies at the individual level. One way of avoiding them is to compare units rather than individuals. It is still necessary to ensure comparability both of the populations served, which is quite feasible given the sub- 
stantial body of knowledge on obstetric risk factors, and of resources and staffing levels.

A randomised controlled trial would have the advantage of controlling for confounding factors, but would introduce the drawback that practice might be altered by the very process of participation. In addition, a trial would be difficult to carry out, for ethical and technical reasons

There are further limitations to reliance on trials which make the development of a reliable observational method necessary. A trial is not feasible if currently accepted practice clearly favours one of the treatment options, as it is too difficult to recruit sufficient randomisable subjects. ${ }^{16}$ In many circumstances, a trial places an undue burden on staffing levels, and doubts may be raised concerning the validity of informed consent in some populations. ${ }^{17}$

The present paper compares groups of obstetric units, categorised according to their CS rates, to see what effect the rate has on a range of outcome variables. By grouping the units, attention is focussed on the CS rate rather than the performance of any particular unit, and any possible variation in ascertainment and reporting is smoothed out. The initial step is to investigate the comparability of the categories by comparing the resources and staffing levels of the obstetric units in each category, the characteristics of the women attending them, and by taking referral patterns into account.

\section{Methods}

SOURCES OF DATA

In the North West Thames Regional Health Authority, which covers a quarter of London and surrounding counties, all obstetric units have been forwarding details of their workload to the regional authority since 1983 . This has enabled accurate data on the birthweight specific perinatal mortality rate (excluding severe malformations) to be assembled for each unit. The analysis is based on all deliveries in 198387: a total of 221,867 deliveries and 1462 perinatal deaths. Data are also available on the CS rate, which enables us to classify units into four categories (see below). It is not possible to disaggregate the $C S$ rate into elective and emergency procedures or to derive birthweight specific CS rates, nor is it possible to disaggregate the perinatal mortality rate into stillbirth and early neonatal mortality rates.

Since 1988, all units have used an on-line perinatal data collection system, the St Mary's Maternity Information System (SMMIS). ${ }^{18}$ Data are entered concurrently by midwives, from the time of booking to the end of the neonatal period, many items being automatically validated at entry. Data can be used for operational purposes within each unit, as well as for audit and for epidemiological analysis. ${ }^{19} \mathrm{~A}$ validation study of SMMIS data has given reassuring results. ${ }^{20}$ This system has enabled a unified database of all 36, 727 singleton pregnancies and deliveries that occurred during 1988 in the 17 (now 15) units within the region to be prepared for analysis.
The units vary in size: in 1988, there were from 859 to 4494 singleton deliveries in each unit. The CS rates varied from $7 \cdot 4$ to $16 \cdot 8 \%$, a more than twofold difference.

Apart from perinatal mortality, the available variables that could be regarded as outcomes of perinatal care are as follows: Apgar scores at one and five minutes, the time of onset of respiration (in minutes), postnatal blood transfusion, evacuation of the retained products of conception (ERPC), postnatal infection, thromboembolism, and haemoglobin ( $\mathrm{Hb}$ ) concentration at the time of discharge from hospital. Additional variables that might be influenced by the method of delivery are the feeding method at discharge (breast, artificial, or supplemented) and the occurrence of puerperal psychosis. These do not comprise a complete set of outcome measures but taken together they provide a good first approximation.

Ideally, the range of outcome variables would include a record of the occurrence and relief of symptoms, and more generally, provision of the service in a way which satisfies its users, for example by giving good information concerning procedures and prognosis and encouraging service users to participate actively in making the decisions that affect them.

\section{METHOD OF ANALYSIS}

For analysis, the range of CS rates was divided into four categories at the cut off points $10.0 \%$, $12.0 \%$ and $15.0 \%$. This was done separately for the two analyses and some units were in different categories in the two time periods.

The highest category ( $>15.0 \%$ ) was found to consist of teaching hospitals, which would be expected to have higher rates both of adverse outcomes and of CS because women at especially high risk are referred to these units, and, in addition, they serve deprived inner city populations.

The other three categories have been designated high $(12 \cdot 0-15.0 \%)$, medium $(10.0$ $12.0 \%)$, and low $(<10.0 \%)$. The focus of interest is primarily on these categories, which consist of maternity units serving their local communities, so that the women who deliver there are representative of the local population in clinical terms, being relatively free of formal and informal selection processes. Approximately $80 \%$ of deliveries in this region take place in these units, the remainder are either in teaching hospitals or in the private sector. It is theoretically possible that differential rates of referral from units of this type to tertiary referral centres could produce a selection effect strong enough to affect the analysis, but an examination of referral patterns does not support this possibility.

The four categories were compared in terms of their levels of neonatal care and their medical and midwifery/nursing staffing levels. Neonatal care was the subject of a survey in 1987, and was divided into three levels: special care baby units, supradistrict neonatal intensive care centres, and regional perinatal centres. Staffing levels in 1983-84 were compared using the medical staffing index (MSI) where 
Table 1 Characteristics of the population served by obstetric units with differing caesarean section rates, 1988

\begin{tabular}{|c|c|c|c|c|c|c|c|c|}
\hline \multirow{3}{*}{$\begin{array}{l}\text { Risk factor } \\
\text { Mean (SD) maternal age }(\mathrm{y}) \\
\text { Mean (SD) maternal height }(\mathrm{cm}) \\
\text { Mean (SD) body mass index }\left(\mathrm{kg} / \mathrm{m}^{2}\right) \\
\text { Mean (SD) birthweight }(\mathrm{g})\end{array}$} & \multicolumn{8}{|c|}{ Caesarean section rate } \\
\hline & \multicolumn{2}{|c|}{$\begin{array}{l}\text { Low } \\
(<10 \%) \\
(n=9344)\end{array}$} & \multicolumn{2}{|c|}{$\begin{array}{l}\text { Medium } \\
\begin{array}{l}(10-12 \%) \\
(n=11260)\end{array}\end{array}$} & \multicolumn{2}{|c|}{$\begin{array}{l}\text { High } \\
\begin{array}{l}(12-15 \%) \\
(n=12813)\end{array}\end{array}$} & \multicolumn{2}{|c|}{$\begin{array}{l}\text { Highest (high risk } \\
\text { populations) } \\
>15 \% \\
(n=3310)\end{array}$} \\
\hline & $\begin{array}{r}28 \cdot 1 \\
161 \cdot 5 \\
23 \cdot 9 \\
3333\end{array}$ & $\begin{array}{c}(5 \cdot 1) \\
(6 \cdot 5) \\
(4 \cdot 0) \\
(548)\end{array}$ & $\begin{array}{r}27 \cdot 7 \\
160 \cdot 7 \\
24 \cdot 2 \\
3293\end{array}$ & $\begin{array}{r}(5 \cdot 2) \\
(6 \cdot 7) \\
(4 \cdot 2) \\
(555)\end{array}$ & $\begin{array}{l}27 \cdot 9 \\
162 \cdot 0 \\
23 \cdot 9 \\
3335\end{array}$ & $\begin{array}{c}(5 \cdot 3) \\
(6 \cdot 8) \\
(4 \cdot 0) \\
(556)\end{array}$ & $\begin{array}{r}28 \cdot 6 \\
162 \cdot 1 \\
24 \cdot 1 \\
3247\end{array}$ & $\begin{array}{r}(5 \cdot 7) \\
(7 \cdot 1) \\
(4 \cdot 2) \\
(604)\end{array}$ \\
\hline & $\%$ & $(\mathrm{No})$ & $\%$ & $(\mathrm{No})$ & $\%$ & $(\mathrm{No})$ & $\%$ & $(\mathrm{No})$ \\
\hline $\begin{array}{l}\text { Very low birthweight }(<1500 \mathrm{~g}) \\
\text { Low birthweight }(<2500 \mathrm{~g}) \\
\text { Primiparous } \\
\text { Cigarette smoking } \\
\text { Ethnic group: Indo-Pakistani } \\
\text { Ethnic group: other non-white }\end{array}$ & $\begin{array}{r}0 \cdot 7 \\
5 \cdot 3 \\
44 \cdot 4 \\
21 \cdot 6 \\
12 \cdot 4 \\
6 \cdot 4\end{array}$ & $\begin{array}{r}(65) \\
(493) \\
(4151) \\
(2013) \\
(1155) \\
(596)\end{array}$ & $\begin{array}{r}0 \cdot 8 \\
6 \cdot 2 \\
44 \cdot 7 \\
22 \cdot 3 \\
20 \cdot 8 \\
11 \cdot 1\end{array}$ & $\begin{array}{r}(89) \\
(701) \\
(5032) \\
(2505) \\
(2311) \\
(1236)\end{array}$ & $\begin{array}{r}0 \cdot 9 \\
5 \cdot 6 \\
45 \cdot 3 \\
21 \cdot 6 \\
12 \cdot 8 \\
6 \cdot 5\end{array}$ & $\begin{array}{r}(116) \\
(717) \\
(5798) \\
(2765) \\
(1632) \\
(831)\end{array}$ & $\begin{array}{r}1 \cdot 9 \\
8 \cdot 3 \\
48 \cdot 9 \\
26 \cdot 9 \\
7 \cdot 9 \\
32 \cdot 6\end{array}$ & $\begin{array}{r}(64) \\
(275) \\
(1620) \\
(885) \\
(261) \\
(1075)\end{array}$ \\
\hline $\begin{array}{l}\text { History of diabetes } \\
\text { History of epilepsy } \\
\text { History of hypertension }\end{array}$ & $\begin{array}{l}0 \cdot 4 \\
0 \cdot 7 \\
4 \cdot 9\end{array}$ & $\begin{array}{r}(38) \\
(67) \\
(459)\end{array}$ & $\begin{array}{l}0 \cdot 4 \\
0 \cdot 7 \\
5 \cdot 6\end{array}$ & $\begin{array}{r}(49) \\
(75) \\
(635)\end{array}$ & $\begin{array}{l}0 \cdot 3 \\
0 \cdot 5 \\
5 \cdot 0\end{array}$ & $\begin{array}{r}(40) \\
(70) \\
(644)\end{array}$ & $\begin{array}{l}0 \cdot 8 \\
0 \cdot 5 \\
5 \cdot 7\end{array}$ & $\begin{array}{l}(28) \\
(16) \\
(188)\end{array}$ \\
\hline $\begin{array}{l}\text { Previous caesarean section } \\
\text { Previous stillbirth (at least 1) } \\
\text { Previous neonatal death } \\
\text { Previous miscarriage } \\
\text { Previous induced abortion }\end{array}$ & $\begin{array}{r}5 \cdot 0 \\
0.9 \\
0 \cdot 8 \\
18 \cdot 2 \\
15 \cdot 8\end{array}$ & $\begin{array}{r}(465) \\
(87) \\
(76) \\
(1705) \\
(1474)\end{array}$ & $\begin{array}{r}5 \cdot 6 \\
1 \cdot 0 \\
0 \cdot 8 \\
17 \cdot 4 \\
16 \cdot 1\end{array}$ & $\begin{array}{r}(636) \\
(114) \\
(92) \\
(1962) \\
(1815)\end{array}$ & $\begin{array}{r}5 \cdot 5 \\
1 \cdot 1 \\
0 \cdot 9 \\
17 \cdot 8 \\
15 \cdot 9\end{array}$ & $\begin{array}{l}(704) \\
(142) \\
(114) \\
(2279) \\
(2033)\end{array}$ & $\begin{array}{r}7 \cdot 3 \\
1.5 \\
1.5 \\
18 \cdot 5 \\
23 \cdot 9\end{array}$ & $\begin{array}{r}(240) \\
(47) \\
(50) \\
(613) \\
(790)\end{array}$ \\
\hline
\end{tabular}

MSI $=\frac{\text { total medical sessions all grades } \times 1000}{\text { annual deliveries }+1 / 2 \text { gynaecology } D \& D s}$

and the number of midwives and nurses per 1000 deliveries. The teaching hospitals tended to have more specialised neonatal care and a higher level of resources than the other three categories, but within the latter there were only slight differences and no clear trend (data available on request).

Table 2 Proportion of each outcome that occurred in deliveries by caesarean section (CS)

\begin{tabular}{lccc}
\hline Outcome variable & $\begin{array}{l}\text { No of CS cases } \\
\text { with this outcome }\end{array}$ & $\begin{array}{c}\text { Total no of cases } \\
\text { with this outcome }\end{array}$ & (\%) \\
\hline Apgar at 1 min $<5$ & 531 & 1369 & $(38 \cdot 8)$ \\
Apgar at 5 mins $<7$ & 239 & 611 & $(39 \cdot 1)$ \\
Onset of respiration $>1$ min & 805 & 3076 & $(26 \cdot 2)$ \\
Postnatal blood transfusion & 232 & 570 & $(40 \cdot 7)$ \\
ERPC & 8 & 169 & $(4 \cdot 7)$ \\
Postnatal infection & 757 & 1471 & $(51.5)$ \\
Thromboembolism & 7 & 24 & $(29 \cdot 2)$ \\
Hb at discharge $<10$ g/100 ml & 711 & 2368 & $(30.0)$ \\
Not breast feeding at discharge & 1920 & 13546 & $(14 \cdot 2)$ \\
Puerperal psychosis & 8 & 21 & $(38 \cdot 1)$ \\
\hline
\end{tabular}

ERCP = evacuation of retained products of conception $\mathrm{Hb}=$ haemoglobin concentration

Table 3 Perinatal mortality in obstetric units with differing caesarean section rates, 1983-87

\begin{tabular}{|c|c|c|c|c|c|c|c|c|}
\hline \multirow[b]{3}{*}{$\begin{array}{l}\text { Birthweight } \\
\text { category }\end{array}$} & \multicolumn{8}{|c|}{ Caesarean section rate } \\
\hline & \multicolumn{2}{|c|}{$\begin{array}{l}\text { Low } \\
\qquad 10 \% \\
(n=41274)\end{array}$} & \multicolumn{2}{|l|}{$\begin{array}{l}\text { Medium } \\
\begin{array}{l}10-12 \% \\
(n=96426)\end{array}\end{array}$} & \multicolumn{2}{|c|}{$\begin{array}{l}\text { High } \\
\begin{array}{l}12-15 \% \\
(n=37050)\end{array}\end{array}$} & \multicolumn{2}{|c|}{$\begin{array}{l}\text { Highest (high risk } \\
\text { populations) } \\
>15 \% \\
(n=47117)\end{array}$} \\
\hline & $\begin{array}{l}\text { Rate per } \\
1000 \text { babies } \\
\text { of stated } \\
\text { weight }\end{array}$ & (No) & $\begin{array}{l}\text { Rate per } \\
1000 \text { babies } \\
\text { of stated } \\
\text { weight }\end{array}$ & (No) & $\begin{array}{l}\text { Rate per } \\
1000 \text { babies } \\
\text { of stated } \\
\text { weight }\end{array}$ & (No) & $\begin{array}{l}\text { Rate per } \\
1000 \text { babies } \\
\text { of stated } \\
\text { weight }\end{array}$ & (No) \\
\hline $\begin{array}{c}500-999 \\
1000-1499 \\
1500-1999 \\
2000-2499 \\
\geqslant 2500 \mathrm{~g}\end{array}$ & $\begin{array}{l}529 \\
206 \\
80 \cdot 3 \\
20 \cdot 2 \\
2 \cdot 13\end{array}$ & $\begin{array}{l}(63) \\
(44) \\
(37) \\
(39) \\
(82)\end{array}$ & $\begin{array}{l}495 \\
199 \\
60 \cdot 8 \\
20 \cdot 7 \\
2 \cdot 45\end{array}$ & $\begin{array}{l}(141) \\
(118) \\
(79) \\
(94) \\
(220)\end{array}$ & $\begin{array}{l}317^{*} \\
143 \\
60 \cdot 1 \\
20 \cdot 7 \\
2 \cdot 24\end{array}$ & $\begin{array}{l}(39) \\
(28) \\
(28) \\
(30) \\
(78)\end{array}$ & $\begin{array}{l}283 \dagger \\
91 \dagger \\
34 \cdot 1 \dagger \\
14 \cdot 0 \\
2 \cdot 34\end{array}$ & $\begin{array}{r}(113) \\
(64) \\
(33) \\
(32) \\
(100)\end{array}$ \\
\hline All & $6 \cdot 42$ & (265) & $6 \cdot 76$ & $(652)$ & $5 \cdot 48$ & (203) & $7 \cdot 26$ & (342) \\
\hline
\end{tabular}

${ }^{*} p<0.001$ : trend for the principal analysis (excluding highest CST category); $\dagger p<0.001$ : trend, all categories included.
Table 1 shows the characteristics of the populations served by the units in each category. Women attending units in the highest category had an increased risk of adverse outcome, owing to a higher proportion of smokers, low birthweight deliveries, and ethnic groups other than white; the two latter variables also predicted an increased likelihood of CS. ${ }^{10}$ In the other three categories, there were no statistically significant differences. In particular, the relatively raised CS rate in the high category could not be explained in terms of factors found to be predictive of an increased rate; and the lack of a trend in height, mean birthweight, low birthweight rate, and the proportion of smokers indicates that there was no social class gradient.

Table 2 shows the proportion of CS cases among the total who experienced each adverse outcome. The CS cases comprised $25-55 \%$ of all cases, for all but two of the variables (ERPC and not breast feeding at discharge); these two variables have been excluded from further analyses.

Statistical analysis was primarily focussed on the principal comparison of the low, medium, and high categories, excluding the highest (teaching hospital/high risk) category. It consisted of performing the $\chi^{2}$ test for trend ${ }^{21}$ for the other three categories in all analyses. In addition, the same test was applied to all four categories for the birthweight specific analysis of perinatal mortality, based on the assumption that in this particular instance, the differential risk between units is adjusted for (possibly overadjusted). A sensitivity analysis was carried out to investigate whether the choice of cut off points had influenced the results unduly: the basic analysis was repeated after the unit with the highest CS rate in each category had been transferred to the category above.

\section{Results}

The variation of perinatal mortality with CS rates (1983-87) is shown in table 3, separately for infants of birthweight $\geqslant 2500 \mathrm{~g}$, and in $500 \mathrm{~g}$ categories below that level. 
When low, medium, and high categories of CS rates were compared, a trend was observed in the lower birthweight groups: units with higher CS rates had more favourable outcomes. For birthweights of $500-999 \mathrm{~g}$, the trend was highly significant $\left(\chi^{2}=11 \cdot 1, \mathrm{p}<0.001\right)$. For birthweights of $1000-1499 \mathrm{~g}$ and $1500-1999 \mathrm{~g}$, the trend was observable but not statistically significant $\left(\chi^{2}=2.52\right.$ and 1.55 , respectively); it disappeared above $2000 \mathrm{~g}$.

If the comparison is extended to include the highest CS rate category (teaching hospitals), the same trend was observed, and to a greater extent (table 3). For the three lowest birthweight groups, statistical significance was achieved at the $0.001 \%$ level $\left(\chi^{2}=42 \cdot 1,34.0\right.$, and 13.5 respectively for $500-999,1000-1499$, and $1500-1999 \mathrm{~g}$ ). The perinatal mortality was also lower in the $2000-2499 \mathrm{~g}$ group for this category compared with the three other CS rate categories, but the trend was not statistically significant $\left(\chi^{2}=2 \cdot 6\right)$. No trend was present above $2500 \mathrm{~g}$.

For the other outcome variables (1988 data), comparing the low, medium, and high rate categories, no trend was observed for Apgar scores, either at one or five minutes (table 4). However, onset of respiration occurring later than one minute was more frequent in the low rate category, the trend being highly significant $\left(\chi^{2}=62.0 ; p<0.001\right)$. The low CS rate category had a higher frequency of late onset of respiration in all birthweight categories (data not shown).

The rate of maternal postnatal blood transfusion increased significantly with $C S$ rate $\left(\chi^{2}=4.1 ; p<0.05\right)$. No significant trend in relation to CS rate was observed for postnatal infection, thromboembolism, the haemoglobin concentration at discharge, or puerperal psychosis.

Overall, the values observed for the high category were higher (less favourable) than those for the medium category for seven out of eight analyses, the exception being the haemoglobin concentration at discharge.

The same grouping of the units by CS rate and the same basic pattern as in table 4 were observed for women with or without a past history of CS, and when primiparae and multiparae were analysed separately. They were also observed when babies weighing less than $2500 \mathrm{~g}$ (total CS rate $1 \cdot 1 \%$ lower), breech deliveries (CS rate $2.3 \%$ lower), or both (CS rate $3.1 \%$ lower) were excluded from the principal analysis. The sensitivity analysis made little impact on the results (data not shown).

\section{Discussion}

For very low birthweight infants, lower perinatal mortality rates were associated with a greater readiness to undertake CS in the population as a whole. Unfortunately, it was not possible to obtain birthweight specific CS rates; this analysis will become possible using the SMMIS system when a larger number of births has accrued.

It is unclear whether birthweight is acting as a proxy for gestational age in this analysis, as the data are not available. Information on the components of perinatal mortality was also unavailable: any difference in mortality would presumably affect intrapartum and neonatal deaths, rather than intrauterine deaths (apart from cases with an antecedent condition in which intervention would have been possible). The presence of the latter dilutes the analysis, making negative results more likely, but this is not relevant to the present study in which a clear effect was demonstrated. These analyses will also be possible using SMMIS.

A similar gradient in normal birthweight deliveries, observed in Czechoslovakian provinces in $1986,{ }^{3}$ was not confirmed in this population. Birthweight specific analysis showed a pattern which would have been obscured by standardisation (which in any case is biased $^{22}$ ).

In addition, the onset of respiration after one minute was more frequent in units which had CS rates below $10 \%$. No other apparent benefits of higher rates were observed.

Higher CS rates were associated with an increased risk of postnatal blood transfusion. Although this finding was not unexpected, it is reassuring that the method is sufficiently sensitive to demonstrate it, as one theoretical problem with this study design is that it could be too insensitive.

The extent to which the results can be generalised to other populations is unclear. To do so, it would be necessary not only to have information on level of risk comparable to table

Table 4 Outcome variables in obstetric units with differing caesarean section rates, 1988

\begin{tabular}{|c|c|c|c|c|c|c|c|c|}
\hline & \multicolumn{8}{|c|}{ Caesarean section rate } \\
\hline & $\begin{array}{l}\text { Low } \\
<10 \% \\
(n=9344) \\
\%\end{array}$ & (No) & \multicolumn{2}{|c|}{$\begin{array}{l}\text { Medium } \\
10-12 \% \\
(n=11260)\end{array}$} & \multicolumn{2}{|c|}{$\begin{array}{l}\text { High } \\
12-15 \% \\
(n=12813)\end{array}$} & \multicolumn{2}{|c|}{$\begin{array}{l}\text { Highest (high-risk } \\
\text { populations) } \\
>15 \% \\
(n=3310)\end{array}$} \\
\hline $\begin{array}{l}\text { Infants (Survivors): } \\
\text { Apgar at } 1 \mathrm{~min}<5 \\
\text { Apgar at } 5 \mathrm{mins}<7 \\
\text { Onset of respiration }>1 \mathrm{~min}\end{array}$ & $\begin{array}{r}3.8 \\
1.6 \\
10.9\end{array}$ & $\begin{array}{r}(351) \\
(147) \\
(1015)\end{array}$ & $\begin{array}{l}3.5 \\
1.5 \\
7.2\end{array}$ & $\begin{array}{l}(387) \\
(170) \\
(812)\end{array}$ & $\begin{array}{l}3.6 \\
1.6 \\
7 \cdot 7 \dagger\end{array}$ & $\begin{array}{l}(459) \\
(210) \\
(983)\end{array}$ & $\begin{array}{l}5 \cdot 3 \\
2 \cdot 6 \\
8 \cdot 0\end{array}$ & $\begin{array}{r}(172) \\
(84) \\
(266)\end{array}$ \\
\hline $\begin{array}{l}\text { Mothers: } \\
\text { Postnatal transfusion } \\
\text { Postnatal infection } \\
\text { Thromboembolism } \\
\text { Hb at discharge }<10 \mathrm{~g} / 100 \mathrm{ml} \\
\text { Puerperal psychosis }\end{array}$ & $\begin{array}{l}1 \cdot 3 \\
4 \cdot 4 \\
0 \cdot 09 \\
5 \cdot 7 \\
0 \cdot 05\end{array}$ & $\begin{array}{r}(124) \\
(410) \\
(8) \\
(528) \\
(5)\end{array}$ & $\begin{array}{l}1 \cdot 4 \\
3 \cdot 5 \\
0 \cdot 03 \\
6 \cdot 2 \\
0 \cdot 04\end{array}$ & $\begin{array}{r}(159) \\
(389) \\
(3) \\
(696) \\
(5)\end{array}$ & $\begin{array}{l}1 \cdot 7^{*} \\
3 \cdot 8 \\
0 \cdot 06 \\
5 \cdot 7 \\
0 \cdot 05\end{array}$ & $\begin{array}{r}(211) \\
(488) \\
(8) \\
(727) \\
(6)\end{array}$ & $\begin{array}{c}2 \cdot 3 \\
5 \cdot 6 \\
0 \cdot 15 \\
12 \cdot 6 \\
0 \cdot 15\end{array}$ & $\begin{array}{r}(76) \\
(184) \\
(5) \\
(417) \\
(5)\end{array}$ \\
\hline
\end{tabular}

${ }^{*} \mathrm{p}<0.05 ;+\mathrm{p}<0.001$ 
1 , but also to be confident that the assumption underlying this analysis holds for other populations - that the distributions of factors predisposing to CS (those affecting the propensity to seek and accept surgical intervention, as well as the risk factors in the table) are similar. At present, there is insufficient evidence to allow a definitive judgement to be made, and it would be prudent to avoid generalising to other places and times.

Some of the findings could possibly be explained in terms other than the CS rate. The improved survival of low birthweight babies in teaching hospitals could reflect higher staffing levels and the presence of on-site neonatal intensive care units, or possibly a more optimistic perception of viability which would encourage greater use of CS. However, this would not explain the gradient seen within the non-teaching hospital category. In addition, a selection process may be in operation, as in utero transfer of mothers of low birthweight infants is more likely in those cases which have a better outlook (the data correspond to the place of delivery, not of booking). However, it is highly improbable that such a process would be of sufficient magnitude to account for the observed findings.

It is also theoretically possible that some units have lower standards for some reason unconnected with $C S$ rates, and that they would (a) resort more often to CS, and (b) tend to have worse outcomes. Such a combination would produce an apparent association of high rates of adverse outcomes with CS rates. This could, for example, occur in a small, isolated unit if obstetric staff were often needed at another site, and paediatric cover was inadequate; however, such units accounted for a tiny proportion of deliveries in this sample, and in any case were spread between the three nonteaching CS rate categories.

Any analysis of this kind rests on the assumption that no important outcomes have been omitted, and that each of the included outcome variables is useful.

For normal birthweight deliveries, the case against a CS rate below $10 \%$ rests on the single variable, onset of respiration after one minute. It is unclear whether or not this represents a significant long term threat to the health of these infants or is an indicator of suboptimal care. Long term follow up of infants with different values of this variable is necessary to answer this question. To attach importance to this finding, it would also be necessary to establish that it is not an artefactual effect such as a systematic difference in recording, as paediatricians tend to be present at CS but not other deliveries.

If the results of the present analysis are applicable to other populations, a high value of this variable would be expected in areas of low CS rates, such as The Netherlands. In the British Births Survey carried out in 1970, the proportion of livebirths with onset of respiration after one minute was $23.5 \%$, a considerably larger figure than in the present study. ${ }^{23}$

The next stage would be a more sophisticated analysis, for example, one confined to certain subpopulations, as the optimal CS rate may vary. Multivariate methods could be used, but with care: as the present findings have demonstrated, important differential patterns within subgroups such as birthweight categories could be obscured. Thus, high risk categories need to be examined in some detail. Secondly, a study of determinants differs from a study of outcomes: a higher CS rate among (for example) women of high socioeconomic status ${ }^{9}$ could be a determinant of the CS rate but is not necessarily optimal in relation to outcomes.

\section{Conclusions}

The results of this study require confirmation before they can be accepted as the basis of firm recommendations. In general (non-tertiary referral) maternity units, no benefit is apparen from a CS rate above 10 to $12 \%$ in the singleton population as a whole; the case against a rate lower than $10 \%$ rests on the single variable, onset of respiration after one minute. However, a more interventionist approach is indicated for very low birthweight infants. Two questions require further research. Is antepartum assessment of birthweight useful in judging the advisability of a CS for very low birthweight deliveries, and what are the implications of onset of respiration after one minute?

A recommendation on the optimal rate and targetting of CS could be incorporated into clinical audit. The CS rate itself can easily be monitored, as can the time of onset of respiration. Using a clinical database like the SMMIS system, it is possible to monitor a range of outcome variables. This could be used to track the effects of a change in practice.

We would like to acknowledge the contribution of all those who have developed the SMMIS database, and have installed, maintained and supported it throughout the North West Thames Region, in particular the midwives in each of the units who enter the data. We would also like to thank Jane Wadsworth, Iain Chalmers, and an anonymous reviewer for helpful comments.

1 Goyert GL, Bottoms SF, Treadwell MC, Nehra PC. The physician factor in cesarean birth rates. $N$ Engl $f$ Med 1989;320:706-9.

2 Notzon FC, Placek PJ, Taffel SM. Comparisons of nationa cesarean section rates. N Engl F Med 1987;316:386-9.

3 Lomas J, Enkin $M$. Variations in operative delivery rates. In Chalmers I, Enkin M, Keirse MJNC, eds. Effective care in pregnancy and childbirth, Vol 2. Oxford: OUP, 1989: 118295.

4 Department of Health and Social Security, Office of Population Censuses and Surveys. Hospital inpatient enquiry. Maternity tables 1982-1985. London: HMSO, 1988. (Series MB4 no 28)

5 Barrett JFR, Jarvis GJ, Macdonald HN, Buchan PC, Tyrrell $\mathrm{SN}$, Lilford RJ. Inconsistencies in clinical decisions in $\mathrm{SN}$, Lilford RJ. Inconsistencies in

6 Janowitz B, Rodrigues W, Covington DL, Arruda JM Morris L. Cesarean delivery in northeast region of Brazil, Morris L. Cesarean delivery in northeast region

7 Anderson GM, Lomas J. Determinants of the increasing cesarean birth rate. $N$ Engl f Med 1984;311:887-92.

8 Haynes de Regt R, Minkoff HL, Feldman J, Schwarz RH. Relation of private or clinic care to the cesarean birth rate. N Engl f Med 1986;315:619-24.

9 Gould JB, Davey B, Stafford RS. Socioeconomic differences in rates of cesarean section. $N$ Engl F Med 1989;321:233-9.

10 Paterson CM, Chapple C, Beard RW, Joffe M, Steer PJ Wright CSW. A proposal for evaluating the quality of maternity services. Br f Obstet Gynaecol 1991;98:1073-8.

11 Maternity Alliance, One birth in nine. Caesarean section trends since 1978. London: Maternity Alliance, 1983.

12 Gleicher N. Cesarean section rates in the United States. The short term failure of the National Consensus Development Conference in 1980. $7 A M A$ 1984;252:3273-6.

13 Clark L, Mugford M, Paterson C. How does the mode of delivery affect the cost of maternity care? $\mathrm{Br} \mathcal{f}$ Obste Gynaecol 1991;98:519-23.

14 O'Driscoll K, Foley M. Correlation of decrease in perinatal mortality and increase in cesarean section rates. Obstet Gynecol 1983;61:1-5. 
15 Williams RL, Hawes WE Cesarean section, fetal monitoring, and perinatal mortality in California. Am $\mathcal{f}$ Public ;69:864-70.

16 Lumley J, Lester A, Renou P, Wood C. A failed RCT to determine the best method of delivery for very low birth weight infants. Controlled Clin Trials 1985;6:120-7.

17 Penn ZJ, Steer PJ. Reasons for declining participation in a prospective randomized trial to determine the optimum mode of delivery of the preterm breech. Controlled Clin Trials 1990;11:226-31.

18 Maresh M, Dawson AM, Beard RW. Assessment of an online perinatal data collection and information system. $\mathrm{Br} f$ Obstet Gynaecol 1986;93:1239-45.

19 Maresh M, Beard RW, Combe D, Dawson AM, Gillmer
MDG, Smith G, Steer PJ. Selection of an obstetric data base for a microcomputer and its use for on-line production of birth notification forms, discharge summaries an perinatal audit. Br ₹ Obstet Gynaecol 1983;90:227-31.

20 CASPE/CPHA. The three hospitals' study. London CASPE, 1992

21 Armitage P, Berry G. Statistical methods in medical research. Oxford: Blackwell Scientific Publications, 1987: 372-4.

22 Wilcox AJ, Russell IT. Perinatal mortality: standardizing for birthweight is biased. Am ₹ Epidemiol 1983;118:857-64

23 Chamberlain G. The First Breath. In: Chamberlain R Chamberlain G, Howlett B, Claireaux A, eds. British birth 1970. London: William Heinemann Medical Books, 1975: 89-117. 